Brit. F. vener. Dis. (1975) 51, 336

\title{
Intensive and prolonged tetracycline therapy in non-specific urethritis
}

\author{
N. HELMY AND W. FOWLER \\ Venereal Disease Department, The General Hospital, Birmingham
}

The tetracycline group of antibiotics is widely accepted as providing the most effective treatment for non-specific urethritis (NSU); it is usually prescribed in a dosage equivalent to tetracycline $250 \mathrm{mg}$. 6-hrly for 4 days. In the majority of cases, the symptoms and signs of urethritis clear quickly with this treatment. Unfortunately, there is a recurrence rate of about 17 per cent. (Morton and Read, 1957), and 3 months after treatment the results of tetracycline therapy are only about 10 per cent. better than those obtained when lactose is given as a placebo (Fowler, 1970).

In the latter paper, it was suggested that:

(1) Recurrences after 4-day tetracycline therapy were much more likely to be relapses than re-infectionsurethroscopic proof of this is evident at times.

(2) Better results might be obtained if tetracycline treatment was more intensive or more prolonged.

(3) Controlled trials should be carried out to try to discover the most effective treatment regime.

In fact, before this paper (Fowler, 1970) was published, a double-blind trial had been initiated in which the treatment was tetracycline $500 \mathrm{mg}$. four times a day for 7 days or $250 \mathrm{mg}$. four times a day for 14 days. The results of this trial suggested that both forms of treatment were more effective than the 4-day course of therapy so far as reducing the recurrence rate was concerned but, curiously, they seemed no better in the long-term.

In an attempt to obtain a more definite answer, it was decided to extend the treatment period and from June 1, 1971, Deteclo $300 \mathrm{mg}$. three times a day for 3 weeks was adopted as the routine treatment for NSU. Deteclo* was prescribed as it had proved in a previous trial to be as effective in NSU as tetracycline and to be remarkably free from side-effects (Fowler and Bernstein, 1969).

*One tablet of Deteclo comprises Demethylchlortetracycline hydrochloride $69 \cdot 2 \mathrm{mg}$., Chlortetracycline hydrochloride $115.4 \mathrm{mg}$., and Tetracycline hydrochloride $115.4 \mathrm{mg}$. (total $300 \mathrm{mg}$.).

Received for publication January 20, 1975
Soon after this long-term treatment was instituted, John (1971) reported that the results of tetracycline therapy in NSU were greatly improved when the antibiotic was given for 3 weeks. Bhattacharyya and Morton (1973) supported John's findings.

In view of this, the 3 weeks' treatment regime was given a prolonged trial, and remained in operation until December 31, 1973, during which time some 3,000 patients were treated. Analysis of the first 10 per cent. (311 cases) produced findings which, when considered together with those of the doubleblind tetracycline trial and of the 4-day tetracycline therapy (Fowler, 1970), produced findings which seemed to be of value in the search for the most effective way of treating NSU. These findings, together with those of the double-blind tetracycline trial, are recorded below.

\section{Cases and management}

400 patients were involved in the double-blind tetracycline trial and, as mentioned above, 311 patients in the Deteclo trial. All were suffering from primary NSU; none was specially selected, had recently suffered from gonorrhoea, received treatment before admission, or had a past history of Reiter's disease.

The investigative procedures, which have previously been described, were designed to discover the common established causes of primary urethritis and to ensure that the condition was, indeed, a primary infection of the urethra.

\section{Treatment}

(A) TETRACYCLINE TRIAL

Treatment was either tetracycline $500 \mathrm{mg}$. four times a day for 7 days or $250 \mathrm{mg}$. four times a day for 14 days. All patients were given 1 tablet Nystatin twice daily by mouth throughout the treatment period. The trial was so designed that the medical staff, including the senior author, had no knowledge of the treatment prescribed. Patients were allotted to one or the other of the treatment groups by the senior charge-nurse or clinic superintendent according to a code devised by the senior pharmacist. Initially, treatment was prescribed for 7 days, patients in the 14-day treatment group being told that a further week's treatment might be necessary.

(B) DETECLO TRIAL

Treatment consisted of one tablet (300 mg.) 8-hrly for 3 weeks. The recommended dose is $300 \mathrm{mg}$. 12-hrly, but 
Black and Whitby (1969) showed that with this dosage blood levels were lower than those obtained with tetracycline hydrochloride $250 \mathrm{mg}$. four times a day and, in view of this, it seemed reasonable to increase the dose of Deteclo. Nystatin tablets 1 twice daily by mouth were also prescribed during the Deteclo treatment. The medicaments were prescribed for a week at a time, the patient having been told initially that treatment would last for 3 weeks.

\section{Follow-up}

Patients were asked to attend weekly for 4 weeks and then, provided there was no clinical evidence of urethritis, fortnightly for the next 2 months. They were advised to abstain from alcohol and to refrain from coitus for at least 2 weeks after apparent cure. Also, patients were asked not to urinate for at least $2 \mathrm{hrs}$ before attending the clinic.

At each examination, any urethral secretion was examined microscopically. (Even the slightest dampness at the meatus was regarded as an indication for making urethral smears). The urine was examined macroscopically and, if necessary, microscopically-e.g. if there were persistent threads in the urine but no obvious discharge. If there was any suggestion of a morning discharge, slides were provided for the patient to make early morning smears.

To ensure the integrity of the double-blind trial, the urine was examined at the second follow-up examination by an independent observer, so that the physician in charge of the case might not discover from the urine that the patient was in the group receiving 14 days' treatment.

\section{Consorts}

Attempts were made to examine the consorts of these patients. Treatment was prescribed only when an established cause of vaginitis or cervicitis was discovered.

\section{Assessment of results}

After the results of treatment had been entered on computer data sheets (Fowler and Leeming, 1969), the code was broken. These results were assessed in the following way:

(1) 'CLEARED'. Signs of urethritis cleared within 3 weeks of starting treatment in the Tetracycline series and within 4 weeks in the Deteclo group, and did not recur within 3 months of the initial examination. (In the past (Fowler, 1970), cases in this category have been classified as 'cured'. 'Cleared' seems a more appropriate term.)

(2) 'FAILED'. Signs of urethritis were still present 3 weeks (tetracycline) or 4 weeks (Deteclo) after starting treatment.

(3) RECURRED. Signs of urethritis cleared as in ' 1 ' but recurred within 3 months of starting treatment. (Before the case was placed in this category, clinical signs of urethritis had to have been absent for at least 2 weeks).

In assessing these results, the occasional presence of a few light threads in the urine, in the absence of any urethral discharge, was not regarded as indicating a treatment failure. However, in the absence of any obvious urethral discharge, the constant presence of urinary threads, which microscopically contained pus cells, was regarded as indicating that treatment had failed.

\section{Results}

Analysis of the results of the double-blind trial was carried out by computer. The Deteclo data sheets were not put through the computer but the results were analysed by statisticians.

TETRACYCLINE (Table)

54 (27 per cent.) of patients given tetracycline for 7 days and 34 ( 17 per cent.) of those given tetracycline for 14 days did not return for any follow-up examination. A further 35 patients (17.5 per cent.) in the 14-day group waited longer than 7 days before returning after the initial examination and had to be eliminated from the trial.

Of the cases treated for 7 days and followed up, 106 (72.6 per cent.) were classed as 'cleared', $31(21 \cdot 2$ per cent.) as 'failed', and nine ( $6 \cdot 1$ per cent.) as 'recurred'. With the 14-day treatment, the corresponding figures were 72.5 per cent. (95 cases), $19 \cdot 1$ per cent. ( 25 cases), and $8 \cdot 4$ per cent. ( 11 cases).

There is no statistical significant difference between these treatments regarding the number of cases recorded as 'cleared' $(t=0.02)$, 'recurred' $(t=0.72)$, or 'failed' $(t=0.44)$.

DETECLO (Table)

Of the patients given Deteclo, 37 (11.8 per cent.) defaulted before the end of the treatment period.

TABLE Results of treating NSU by various schedules

\begin{tabular}{|c|c|c|c|c|c|c|c|c|c|c|}
\hline \multicolumn{3}{|l|}{ Treatment } & \multirow{3}{*}{$\begin{array}{l}\text { No. } \\
\text { treated }\end{array}$} & \multirow{3}{*}{$\begin{array}{l}\text { No. } \\
\text { followed }\end{array}$} & \multicolumn{6}{|c|}{ Result } \\
\hline \multirow{2}{*}{ Drug } & \multirow{2}{*}{$\begin{array}{l}\text { Dose } \\
\text { (mg.) }\end{array}$} & \multirow{2}{*}{ Duration } & & & \multicolumn{2}{|c|}{ Cleared } & \multicolumn{2}{|c|}{ Failed } & \multicolumn{2}{|c|}{ Recurred } \\
\hline & & & & & No. & Per cent ${ }^{\mathrm{a}}$ & No. & Per cent ${ }^{\mathrm{a}}$ & No. & Per cent ${ }^{\mathrm{a}}$ \\
\hline \multirow{2}{*}{$\begin{array}{l}\text { Tetracycline } \\
\text { (double-blind } \\
\text { trial) }\end{array}$} & 500 & $\begin{array}{l}4 \text { times a day } \\
\text { for } 7 \text { days }\end{array}$ & 200 & 146 & 106 & $72 \cdot 6$ & 31 & $21 \cdot 2$ & 9 & $6 \cdot 2$ \\
\hline & 250 & $\begin{array}{l}4 \text { times a day } \\
\text { for } 14 \text { days }\end{array}$ & 200 & 131 & 95 & $72 \cdot 5$ & 25 & $19 \cdot 1$ & 11 & $8 \cdot 4$ \\
\hline Deteclo & 300 & $\begin{array}{l}3 \text { times a day } \\
\text { for } 3 \mathrm{wks}\end{array}$ & 311 & 274 & 202 & $73 \cdot 7$ & 66 & $24 \cdot 0$ & 6 & $2 \cdot 2$ \\
\hline Oxytetracycline & 250 & $\begin{array}{l}4 \text { times a day } \\
\text { for } 4 \text { days }\end{array}$ & 289 & 228 & 166 & $72 \cdot 8$ & 51 & $22 \cdot 4$ & 11 & $4 \cdot 8$ \\
\hline
\end{tabular}


This is a remarkably low figure for this Clinic. A low default rate was a marked feature also of the trial carried out by Bhattacharyya and Morton (1973) and, although no attention is drawn to it, would appear to have been a feature of the trial reported by John (1971). It was formerly thought that the low default rate could have been partly due to selection of cases, but it was more probably due to the detailed explanation given by the nursing staff. However, no special measures were taken in our Deteclo trial other than to emphasize that treatment would last for 3 weeks but would be prescribed only for a week at a time. This emphasis on the duration of treatment would seem to be the reason for the low default rate and it might well be that the default rate would have been improved in the double-blind Tetracycline trial had patients been told firmly that treatment would last for 2 weeks.

Of the cases followed, 73.7 per cent. (202) were recorded as 'cleared', 24 per cent. (66) as 'failed', and $2 \cdot 2$ per cent. (6) as 'recurred'.

\section{Discussion}

The double-blind trial was badly designed and would have been more instructive had the daily dose of tetracycline or the time during which the antibiotic was administered been the same for both treatment regimes. As it is, the trial only indicates that the total amount of antibiotic given is more important in the treatment of NSU than the duration of treatment.

At first glance it would appear that $14 \mathrm{~g}$. tetracycline in 7 or 14 days was more effective than $4 \mathrm{~g}$. in 4 days (Fowler, 1970). However, the latter results were assessed 14 days after treatment started and had the assessment been carried out a week later, i.e. at the same time as in the double-blind trial, the percentage of 'cleared' cases would have been similar to that in the latter trial. It would appear likely that the treatments given in the double-blind trial are no more effective in NSU than tetracycline $250 \mathrm{mg}$. four times a day for 4 days. (Unfortunately, it is not possible to say what the recurrence or failure rates would have been after the 4-day tetracycline treatment had the results been assessed at 3 weeks, but it is pertinent to note that at 2 weeks the recurrence rate was 16.7 per cent. and the frank failure rate 10.5 per cent.) (Fowler, 1970).

The findings in the Deteclo series are by no means as impressive as those obtained by Bhattacharyya and Morton (1973) with a smaller amount of Deteclo (300 mg. 12-hrly for 3 weeks). Nor are they as good as those reported by John (1971) after oxytetracycline $250 \mathrm{mg}$. 6-hrly for the same length of time, although experience in this Clinic indicates that Deteclo is not inferior to the other tetracyclines in the treatment of NSU (Fowler and Bernstein, 1969).

Indeed, the results of long-term Deteclo therapy are superior to those of the double-blind trial only so far as the recurrence rate, which was significantly lower, is concerned. Despite this greatly improved recurrence rate, the percentage of cases cleared with Deteclo does not differ significantly from the percentage of cases cleared with the tetracycline therapy in the double-blind trial, nor with the 4-day tetracycline therapy when the results are assessed 14 days after starting treatment (Fowler, 1970).

This must mean that the recurrence rate is not mainly an indication of relapses or re-infections; indeed, if Tables I and II are considered together with the recurrence and failure rates noted earlier for the 4-day tetracycline regime (Fowler, 1970) and remembering that these results were assessed 4,3 , and 2 weeks respectively after starting treatment, it will be seen that the recurrence rate appears to depend to a great extent upon the time at which the results are read, and that the longer the interval between starting treatment and assessing results, the lower the recurrence rate and the corresponding increase in the failure rate. It is easy to appreciate how this could happen. A patient showing no signs of urethritis at 14 days but presenting signs at 4 weeks would be classified as a recurrence if the results were assessed at $\mathbf{1 4}$ days and as a failure if the assessment was made at 3 to 4 weeks.

That this is probably true is indicated by the findings in a double-blind trial in which oxytetracycline $250 \mathrm{mg}$. four times a day for 4 days was used as the control in an evaluation of minocycline in NSU (Fowler, 1974). The results were assessed mainly at 4 weeks. The Table shows that the findings parallel those obtained in the Deteclo trial. The slight difference in the recurrence rate is not statistically significant $(t=1 \cdot 33)$.

In a condition with such a varied aetiology as NSU, the only way to obtain accurate information regarding the efficacy of medicaments is to compare these with one another, or with a placebo, in a double-blind trial. As the trials dealt with in this paper were carried out at different times, the conclusions arrived at by comparing the various findings are not necessarily accurate. Nevertheless, there is a very strong suggestion that neither increasing the duration of tetracycline therapy to 3 weeks nor doubling the daily dose of tetracycline offers any advantages over the customary dosage of tetracycline $250 \mathrm{mg}$. four times a day for 4 days.

\section{Summary and conclusion}

Details are given of a double-blind trial involving 400 cases in which tetracycline $500 \mathrm{mg}$. four times a day for 7 days was compared with tetracycline $250 \mathrm{mg}$. four times a day for 14 days and also of the findings in 311 cases treated with Deteclo $300 \mathrm{mg}$. three times a day for 3 weeks. 
The treatments in the double-blind trial were equally effective and appeared to be as effective as the long-term Deteclo therapy. When the results of these treatments were compared with those obtained previously with tetracycline $250 \mathrm{mg}$. four times a day for 4 days and allowance was made for the time at which the latter results had been assessed, it was concluded that neither the treatments used in the double-blind trial nor Deteclo $300 \mathrm{mg}$. three times a day for 3 weeks offered any advantage over the customary treatment with tetracycline $250 \mathrm{mg}$. four times a day for 4 days.

\section{References}

Bhattacharyya, M. N., and Morton, R. S. (1973) Brit. F. vener. Dis., 49, 521

Black, H. J., and WhItBY, J. L. (1969) Clin. Trials f., 6, 128

FowLER, W. (1970) Brit. F. vener. Dis., 46, 464 (1974) Brit. F. clin. Pract., 28, 347

and Bernstein, L. S. (1969) Clin. Trials f., 6, 157

and Leeming, R. J. (1969) Brit. f. vener. Dis. 45, 287

JoHN, J. (1971) Ibid., 47, 266

MORTON, R. S., and READ, L. (1957) Ibid., 33, 223 